Reference: Biol. Bull. 182: 231-240. (April, 1992)

\title{
Antipredator Defenses in Tropical Pacific Soft Corals (Coelenterata: Alcyonacea). I. Sclerites as Defenses Against Generalist Carnivorous Fishes
}

\author{
KATHRYN L. VAN ALSTYNE ${ }^{1}$, CHAD R. WYLIE, \\ VALERIE J. PAUL, AND KAREN MEYER \\ University of Guam Marine Laboratory, UOG Station, Mangilao, Guam 96923
}

\begin{abstract}
Calcified sclerites are common in many invertebrate species and are frequently used as taxonomic indicators; however, little is known about the function of sclerites. To determine whether sclerites could function as antipredator defenses, we conducted field assays in which sclerites from the Indo-Pacific soft corals Sinularia maxima, $S$. polydactyla, and $S$. sp. were incorporated into an artificial diet and offered to a natural assemblage of fishes in the field. Sclerites from both the tips and bases of all three species of Sinularia reduced feeding by a natural assemblage of generalist carnivorous fishes off Guam by $27-44 \%$; however, sclerites from the bases of the colonies were $18-51 \%$ more deterrent than tip sclerites. The greater effectiveness of sclerites from the bases of the colonies was largely attributable to their high concentrations. Sclerites in the tips of the colonies occurred in mean concentrations from 24 to $58 \%$ by dry weight and were generally less than $0.5 \mathrm{~mm}$ in length. Sclerites in the bases of the colonies were larger and occurred in average concentrations of $82-88 \%$. Sinularia sclerites were increasingly effective as feeding deterrents with increasing concentration at concentrations less than $30-50 \%$ by dry weight. The effectiveness of sclerites as deterrents leveled off at higher concentrations. Sclerite morphology was also important in determining antipredator activity. Although sclerites can play a role in predator deterrence, they can also function in the structural support of colonies. Thus, the sizes, shapes, and abundances of sclerites at different locations within colonies will be determined by their
\end{abstract}

Received 11 July 1991; accepted 23 January 1992.

${ }^{1}$ Present Address: Department of Biology, Kenyon College, Gambier, Ohio 43022. functions at particular locations as well as constraints upon their use or production.

\section{Introduction}

Soft corals are frequently a conspicuous component of shallow, Indo-Pacific tropical reef communities despite the abundance of carnivorous fishes. For example, on Guam, soft corals have been reported to provide $\sim 95 \%$ of the total living animal cover on some reefs (Wylie and Paul, 1989). On New Guinean reefs, soft corals constitute approximately $50 \%$ of the living cover between depths of 0 and $5 \mathrm{~m}$ (Tursch and Tursch, 1982).

The persistence of soft corals and gorgonians in areas with high levels of predation has previously been attributed to their production of predator-deterrent secondary metabolites (Coll et al., 1983; LaBarre et al., 1986; Pawlik et al., 1987; Wylie and Paul, 1989); but, soft corals and gorgonians also produce sclerites or spicules that could potentially serve as antipredator defenses (Harvell and Suchanek, 1987; Sammarco et al., 1987; Harvell et al., 1988; Harvell and Fenical, 1989). Mineral-hardened spicules are common within a number of invertebrate groups including sponges, cnidarians, platyhelminth worms, mollusks, echinoderms, and ascidians (Kingsley, 1984). However, despite the widespread occurrence of sclerites within marine invertebrates, little is known about the function of these structures, in particular, their ability to deter feeding by potential predators.

Only in recent studies has the role of sclerites as antipredator defenses been explored. When incorporated into an artificial diet, sclerites of the gorgonian sea whip Pseudopterogorgoria acerosa deterred feeding by carnivorous fishes in field assays in Belize (Harvell et al., 1988). Scler- 
ites of the Caribbean gorgonian Gorgonia ventalina deter feeding by natural assemblages of fishes in the field and by the gorgonian specialist Cyphoma gibbosum (Van Alstyne and Paul, in press). Toxicity of soft corals to the mosquito fish Gambusia affinis was negatively correlated with the degree of armament of the polyps in the Nephthedidae and negatively correlated with the degree of mineralization of the coenenchyme in 14 species of Sinularia (Sammarco et al., 1987). Alcyonarian sclerites are extremely variable in size and morphology and are frequently used as taxonomic characters (e.g., Bayer, 1956, 1961; Bayer et al., 1983). Seasonal fluctuations in collagen levels in the organic matrix of sclerites indicate that these structures are dynamic and may undergo seasonal cycles of demineralization and remineralization (Kingsley et al., 1990).

In this paper, we provide direct experimental evidence that sclerites from the alcyonian soft corals Sinularia spp. serve as antipredator defenses to generalist carnivorous fishes in the field. Soft corals of the genus Sinularia are widely distributed throughout the Indo-Pacific region (Verseveldt, 1977, 1980), and are an important component of shallow coral reef communities on Guam (Gawel, 1977). Sinularia spp. generally have a lobate morphology with an upper portion that contains polyps, and a lower sterile stalk (Verseveldt, 1977). The surface of the lobes contains small club-shaped sclerites, rods, and spindles (Verseveldt, 1980). We also document differences in sclerite morphologies and densities within soft coral colonies and explore the consequences of these differences in deterring feeding by fishes.

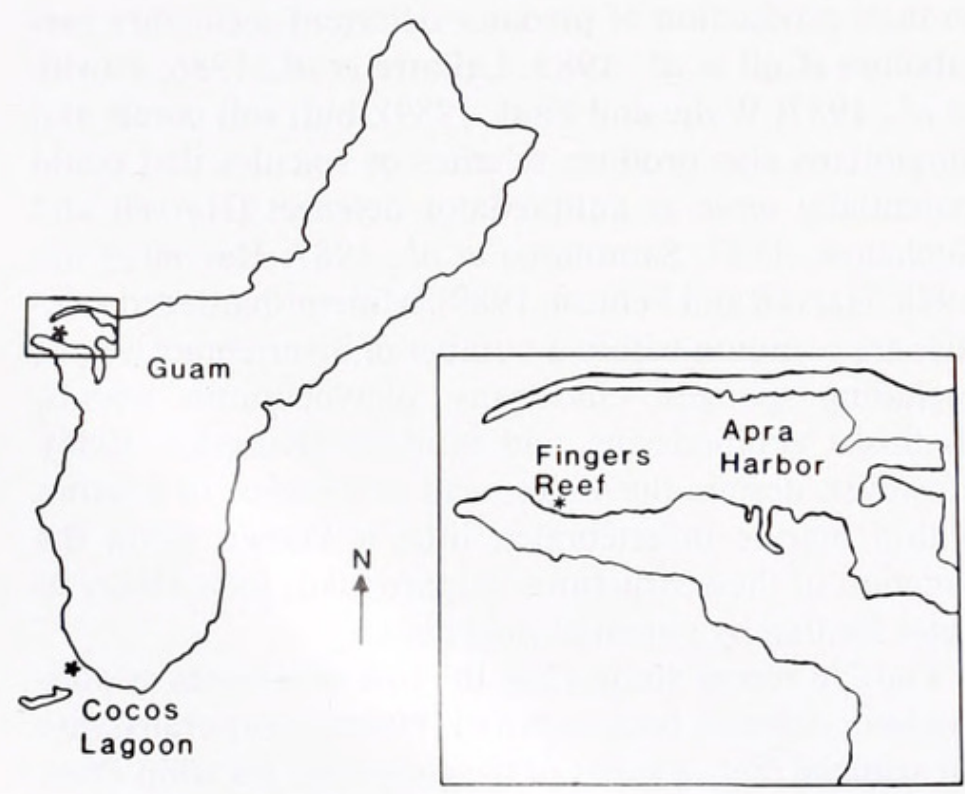

Figure 1. Locations of the Fingers Reef and Cocos Lagoon study sites on Guam.

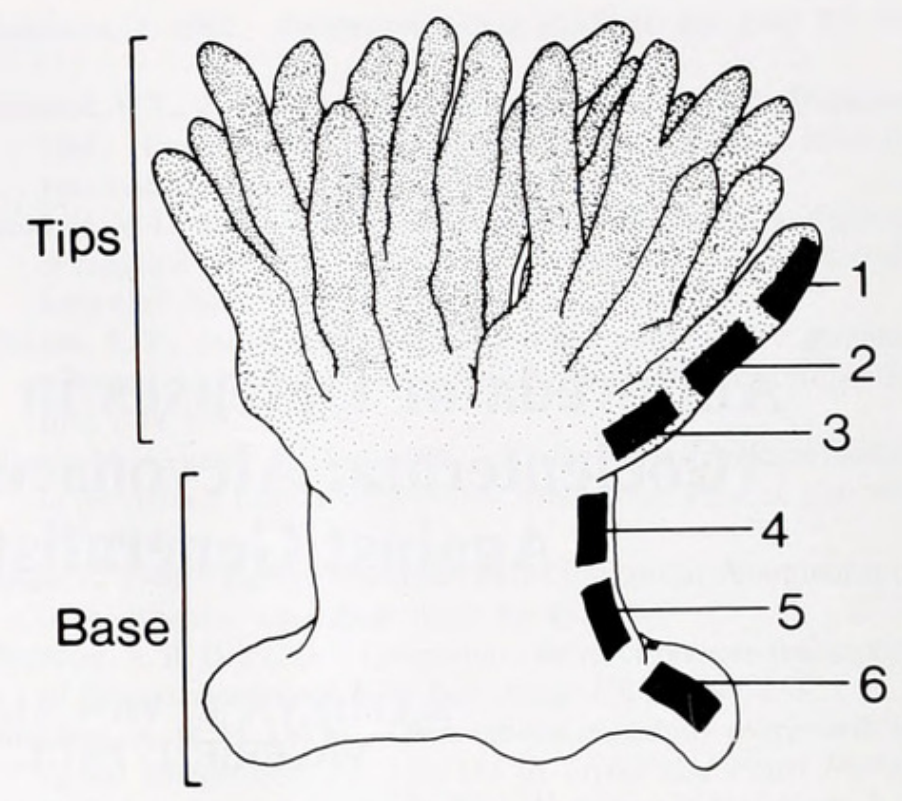

Figure 2. Sampling locations within an individual Sinularia colony. Three transects of six samples each were made from the tips of the colony to the base of the colony. Transects ran from the most distal tips of the colonies (location 1) to the point of attachment at the base of the colony (location 6)

\section{Materials and Methods}

\section{Study sites}

Sinularia maxima, $S$. polydactyla, and $S$. sp. were collected from a patch reef in Cocos Lagoon, Guam, USA (Fig. 1). This reef has been previously described by Paul and Van Alstyne (1987) and Wylie and Paul (1989). It is a small patch reef, $\sim 35 \mathrm{~m} \times 50 \mathrm{~m}$, that is composed mainly of dead Acropora. Soft corals comprise $\sim 10 \%$ of the cover of the reef (Wylie, 1988).

All feeding experiments took place on Fingers Reef in Apra Harbor, Guam. The reef at Fingers (Fig. 1) is composed of a diverse assemblage of scleractinian corals, as well as many unidentified species of Sinularia. Numerous species of herbivorous and carnivorous fish inhabit this reef. The fishes that were observed to feed on ropes during feeding experiments included sergeant majors (Abudefduf spp.), damselfish (Amblyglyphidodon curacao), wrasses (Cheilinus fasciatus, Gomphosus varius, Halichoeres trimaculatus), and triggerfish (Balistapus undulatus).

\section{Quantification of sclerite concentrations}

Five soft corals each of Sinularia maxima, S. polydactyla, and $S$. sp. were collected from Cocos Lagoon. Six samples of $\sim 2 \mathrm{~cm}$ (height) $\times 1 \mathrm{~cm}$ (length) $\times 1 \mathrm{~cm}$ (width) were removed from each of three "transects" of each colony. The transects ran from the most distal part of the tips to the point of attachment at the base (Fig. 2). These samples areas will be referred to as locations \#1 (most 
distal tip sample) through \#6 (base sample closest to the attachment point of the colony). Eighteen samples were taken from each of the 15 colonies. Sclerites concentrations from each sample were quantified as described in Van Alstyne and Paul (in press).

An analysis of variance was used to test for differences in mean sclerite concentrations among species, among individuals within a species, among transects within an individual, and among locations. A mixed model ANOVA was conducted with the factors being (1) species, (2) individuals nested within species, (3) transects nested within individuals, and (4) locations along the transects from the tips to the bases of the colonies. The analysis was conducted with an SPSSPC + statistical package.

\section{Measurement of sclerites}

Sclerites from the samples taken above were used to obtain measurements of sclerite sizes within colonies. Measurements of maximum sclerite length were made from 100 to 200 sclerites from each sample using a video image analysis system. All of the sclerites in at least two randomly selected fields from each of three subsamples from each sample were measured to the nearest $\mu \mathrm{m}$ at magnifications ranging from $60 \times$ to $500 \times$ using a JAVA computer program.

Sclerite masses were estimated by using a log-log regression of sclerite masses to lengths. To obtain the regression, 15-20 sclerites from each species were measured to the nearest $\mu \mathrm{m}$ with a video image analysis system and then weighed to the nearest $0.01 \mathrm{mg}$. The regression equations for each species were: $S$. maxima: $\operatorname{mass}(\mathrm{g})$ $=\mathrm{e}^{-26.85+3.10^{*} \ln [\text { length }(\mu \mathrm{m})]}\left(\mathrm{n}=20, \mathrm{r}^{2}=0.696, P<0.05\right), S$. polydactyla: $\operatorname{mass}(\mathrm{g})=\mathrm{e}^{-18.80+2.15^{*} \ln [\operatorname{length}(\mu \mathrm{m})]}\left(\mathrm{n}=20, \mathrm{r}^{2}\right.$ $=0.802, P<0.05), S$. sp: $\operatorname{mass}(\mathrm{g})=\mathrm{e}^{-20.00+2.41^{*} \operatorname{In}[\text { length }(\mu \mathrm{m})]}$ (n $\left.=15, \mathrm{r}^{2}=0.960, P<0.05\right)$.

\section{Extraction of sclerites for feeding assays}

Approximately 15 individuals each of 3 soft coral species were collected from Cocos Lagoon. Tissues at the bases of the soft corals were separated from the tips and lobes (sensu Wylie and Paul, 1989). The polyp-bearing, top $10-15 \mathrm{~cm}$ of the colonies will hereafter be referred to as the tips (Fig. 2). The pieces from all individuals of a species were combined and extracted twice in 1:1 methylene chloride:methanol. The organic extracts were removed, and the remaining soft coral pieces were dried, then digested in bleach until no organic material remained. The sclerites were rinsed five to eight times in tap water, then once with acetone, and dried. Examination of sclerites using light microscopy and scanning electron microscopy showed no signs of sclerite deterioration due to the extraction process.

\section{Two-choice feeding experiments}

Sclerites from soft coral tips and bases were incorporated into an artificial diet consisting of $2.5 \mathrm{~g}$ carrageenan (Sigma \#C-1013), $4 \mathrm{~g}$ of paraffin wax, and $70 \mathrm{ml}$ water, heated in a microwave oven for $75 \mathrm{~s}$. After the wax/carrageenan mixture was heated, $\sim 50 \mathrm{~g}$ of squid homogenate ( $250 \mathrm{ml}$ water: $500 \mathrm{~g}$ squid) and sclerites were added. Concentrations of sclerites used in these feeding experiments are listed in Table I. These values are within the ranges of concentrations measured in bases and tips of Sinularia spp. in this study. Controls consisted of the artificial diet without sclerites. The diet was then poured into stainless steel potato slicers that were composed of a $7 \times 7$ grid of $1 \mathrm{~cm} \times 1 \mathrm{~cm}$ squares that were $\sim 1 \mathrm{~cm}$ high. Prior to the addition of the diet, black plastic o-rings $(3 / 8$ in OD, $1 / 4$ in ID) were placed in each cube in the potato slicer. After the diet had gelled, it was removed from the mold and attached to ropes to be placed out in the field. The diet was presented to fishes on $50 \mathrm{~cm}$ long pieces of 3 strand, $1 / 4$ in yellow polypropylene rope in which four $3-\mathrm{cm}$ long safety pins were attached equidistantly along the top 30$40 \mathrm{~cm}$ of the rope (Fig. 3).

The ropes were placed on the reef in pairs by attaching them to pieces of coral. All experiments were done on Fingers Reef in Apra Harbor, Guam, at a depth of 5-8 m. Pairs of ropes were placed on the reef and removed when at least four of the eight pieces of artificial diet on the two ropes had been completely consumed. Each experiment consisted of 17-21 pairs of ropes. Differences in consumption were compared with a Wilcoxon Signed Ranks test $(\alpha=0.05)$.

Feeding experiments at Fingers Reef consisted of the following paired experiments: (1) comparisons of feeding rates on control diet versus diet containing either tip sclerites or base sclerites at natural concentrations (Table I), (2) comparisons of feeding rates on control diet and diet containing either tip or base sclerites at $10 \%, 25 \%$, or $50 \%$ by dry weight, and (3) comparisons of diet containing tip sclerites at natural concentrations with diet containing base sclerites at natural concentrations. Each of the experiments described above was conducted with all three species of Sinularia.

\section{Table I}

Concentrations (as percent of dry weight) of sclerites used in feeding assays

\begin{tabular}{lcc}
\hline \hline & Tips & Bases \\
\hline Sinularia maxima & $31 \%$ & $81 \%$ \\
S. polydactyla & $41 \%$ & $76 \%$ \\
S. sp. & $47 \%$ & $82 \%$ \\
\hline
\end{tabular}




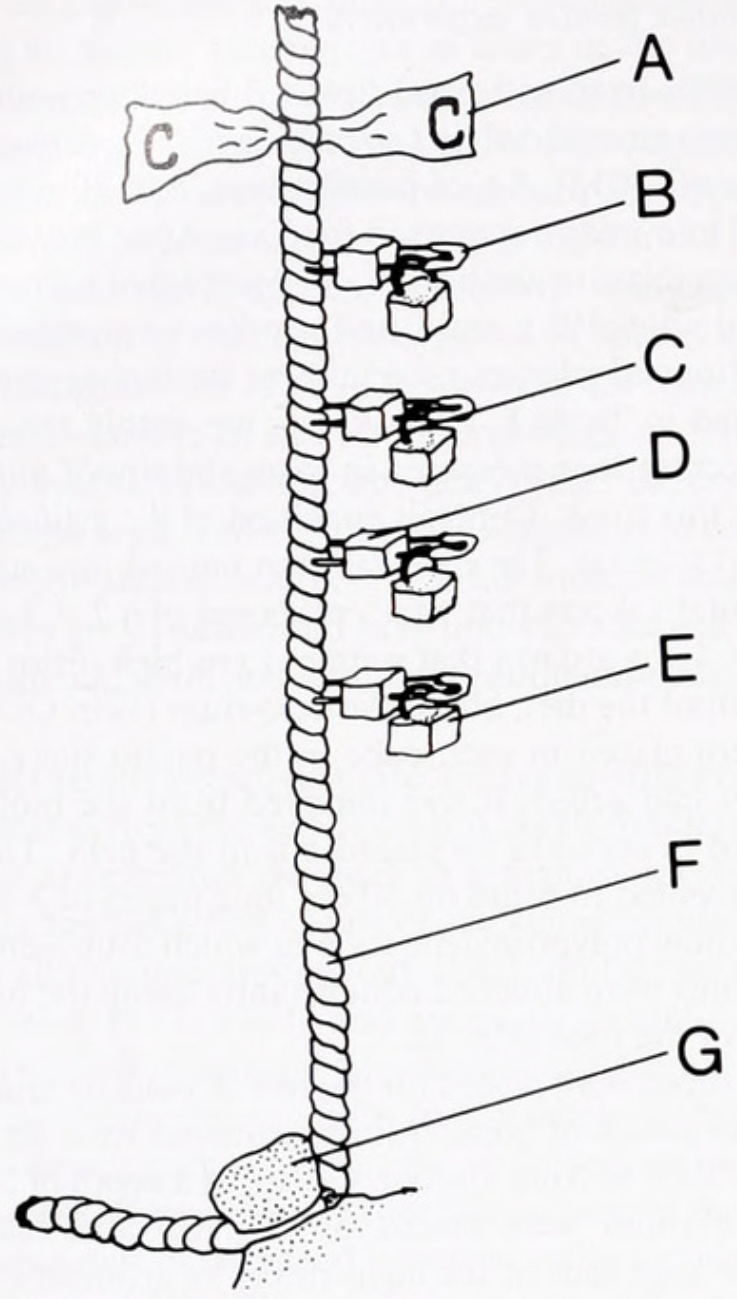

Figure 3. Rope used in a feeding assay. The assay consisted of attaching an o-ring $(\mathrm{C})$ embedded within a piece of artificial diet (E) to a safety pin (B). The safety pins were attached to a $0.5 \mathrm{~m}$ piece of 3 -strand polypropylene rope $(\mathrm{F})$ and were buoyed with small pieces of neoprene (D). The ropes were attached in the field to pieces of coral (G). Ten-cm pieces of labelled surveyor's tape (A) were used to distinguish ropes containing different types of diet. A single rope held only one type of diet.

\section{Four-choice feeding experiments}

To determine the relative effects of sclerite morphologies and concentrations on feeding deterrence, fishes were offered artificial diets containing two types of sclerites (tip and base) at two different concentrations (tip concentrations and base concentrations). Thus, fishes were offered tip sclerites at natural tip concentrations, tip sclerites at natural base concentrations, base sclerites at natural tip concentrations, and base sclerites at natural base concentrations. Separate experiments were conducted for each of the three Sinularia species.

Artificial diets were attached to polypropylene ropes and offered to fishes in the field in the same manner as described for the two-choice experiments, with the exception that a set of four ropes were offered instead of a pair of ropes. Each of the four ropes contained one of the four diets described above; each of the four types of diet was presented in each replicate $(n=19$ or 20$)$. Ropes were removed and the number of pieces of each diet remaining on each rope were counted after fishes had consumed at least half of the sixteen pieces of diet in the set. Statistical analyses were conducted with a two-way Kruskal-Wallis test. Factors used in the analysis were sclerite type and sclerite concentration.

\section{Results}

\section{Distribution and abundance of sclerites}

Dry weight concentrations of sclerites differed among the three species of Sinularia and among locations within the colonies (Table II). In general, sclerite concentrations (as \% of dry weight) increased from the tips of the colonies to their bases (Fig. 4). Mean concentrations at the tips of the colonies ranged from $24 \%$ in S. polydactyla to $58 \%$ in $S$. sp. Mean concentrations of sclerites in the most basal portion of the colonies ranged from $82 \%$ in $S$. maxima to $88 \%$ in $S$. sp.

The size distributions of sclerites also showed considerable intra-colony variation. Almost all of the sclerites in the most distal tips of the colonies of the three species of soft corals were less than $0.5 \mathrm{~mm}$ in length (Figs. 5-7). However, in $S$. sp., the majority of the mass of the sclerites in the most distal tips were comprised of sclerites that were greater than $0.5 \mathrm{~mm}$ long; the largest fraction by mass was $1.0-1.5 \mathrm{~mm}$ long (Fig. 5). In the most distal tips of $S$. polydactyla, approximately $55 \%$ of the sclerite mass was comprised of sclerites less than $0.5 \mathrm{~mm}$ in length (Fig. 6 ); and, in $S$. maxima, all of the mass of the sclerites in the most distal tips was in the $<0.5 \mathrm{~mm}$ category (Fig. 7).

Larger sclerites increased in abundance in the more basal portions of the colonies of all three soft coral species (Figs. 5-7). Even in the most basal samples, sclerites less than $0.5 \mathrm{~mm}$ long were numerically abundant; however, they made up only a small fraction of the total sclerite

Table II

Analysis of variance of sclerite concentrations in Sinularia spp.

\begin{tabular}{lrrrrr}
\hline \hline \multicolumn{1}{c}{ Source } & df & \multicolumn{1}{c}{ SS } & \multicolumn{1}{c}{ MS } & \multicolumn{1}{c}{ F } & $P$ \\
\hline Species & 2 & 12,130 & 6,065 & 10.39 & 0.000 \\
Individual (species) & 12 & 8,363 & 697 & 1.19 & 0.288 \\
Transect (individual) & 10 & 6,483 & 648 & 1.11 & 0.355 \\
Location & 5 & 55,625 & 11,124 & 19.06 & 0.000 \\
Error & 240 & $\underline{140,071}$ & 584 & & \\
Total & 269 & $\frac{22,672}{22,672}$ & & & \\
\hline
\end{tabular}

A mixed model ANOVA was conducted with the factors being (1) species, (2) individuals nested within species, (3) transects nested within individuals, and (4) locations along the transects from the tips to the bases of the colonies. 


\section{Sclerite Concentrations}

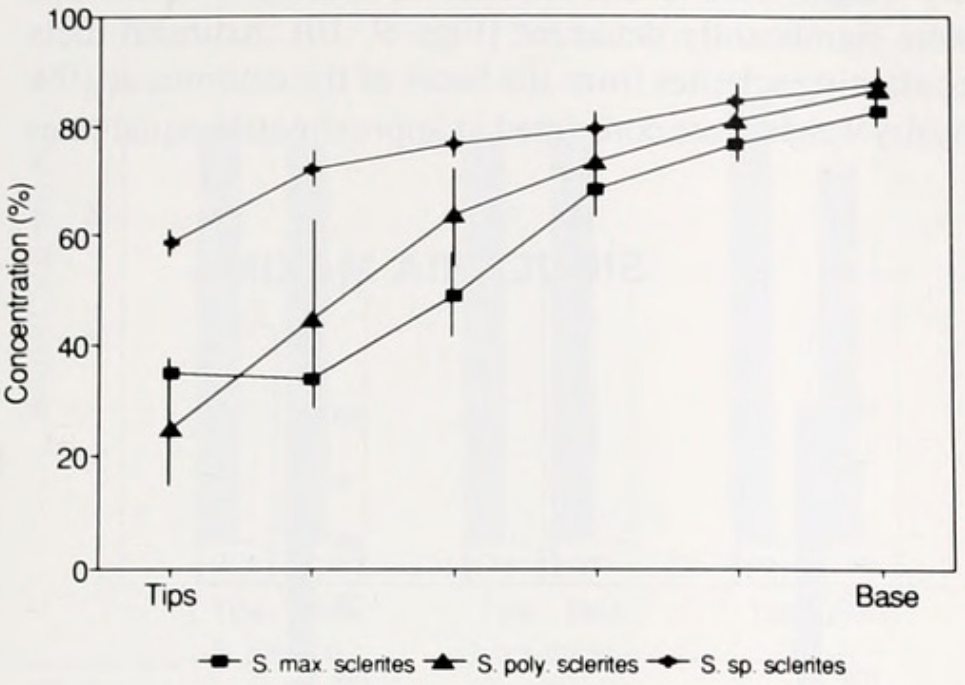

Figure 4. Sclerite concentrations (as \% of dry weight) within colonies of Sinularia spp. Samples were obtained from five colonies of each of the three species. The samples correspond with locations 1 (tips) through 6 (base) shown in Figure 2. Horizontal bars represent \pm 1 SD.

mass. In the most basal samples, the largest fractions of sclerites by mass were in the $1.0-1.5 \mathrm{~mm}$ size class in $S$. maxima (Fig. 7) and in the $1.5-2.0 \mathrm{~mm}$ size class in $S$. polydactyla (Fig. 6) and $S$. sp. (Fig. 5). Thus, in all three species of Sinularia examined in this study, sclerites increased in both size and concentration from the tips of the colonies to the bases.

Sclerites in $S$. maxima ranged in length from 0.06 to $5.0 \mathrm{~mm}$. The largest sclerites in S. maxima were elongated spindles with complex tubercles (sensu Bayer et al., 1983). The small sclerites ( $<0.5 \mathrm{~mm}$ long) were rods with volcano-like processes and wart clubs (sensu Bayer et al., 1983). Wart clubs were proportionately more abundant in the tips than the bases of $S$. maxima. The large sclerites ( $>0.5 \mathrm{~mm}$ long) of $S$. polydactyla were comprised primarily of spindles with complex tubercles. Most of the spindles were straight; however, a few were bent. The small sclerites were either thorn clubs or rods with volcano-like processes. Sclerites from $S$. polydactyla ranged in length from 0.08 to $5.0 \mathrm{~mm}$. In $S$. sp., the larger sclerites were comprised of spindles with complex tubercles, thorn stars, and thorn scales. The spindles were frequently bent and occasionally bifurcated on one end. The tubercles on the spindles of $S$. sp. were smaller than those on $S$. maxima and $S$. polydactyla. The smaller sclerites were rods and thorn clubs. Sclerites from $S$. sp. ranged in length from 0.08 to $4.6 \mathrm{~mm}$.

\section{Effectiveness of sclerites as feeding deterrents}

At natural concentrations, all of the sclerites from the bases and the tips of all three species of Sinularia were significantly $(P<0.05)$ deterrent to fishes at Fingers Reef (Fig. 8). The addition of sclerites from the tips of Sinularia spp. reduced feeding by $33-44 \%$, whereas sclerites from the bases of the colonies reduced feeding by $27-33 \%$.

\section{SINULARIA SP.}

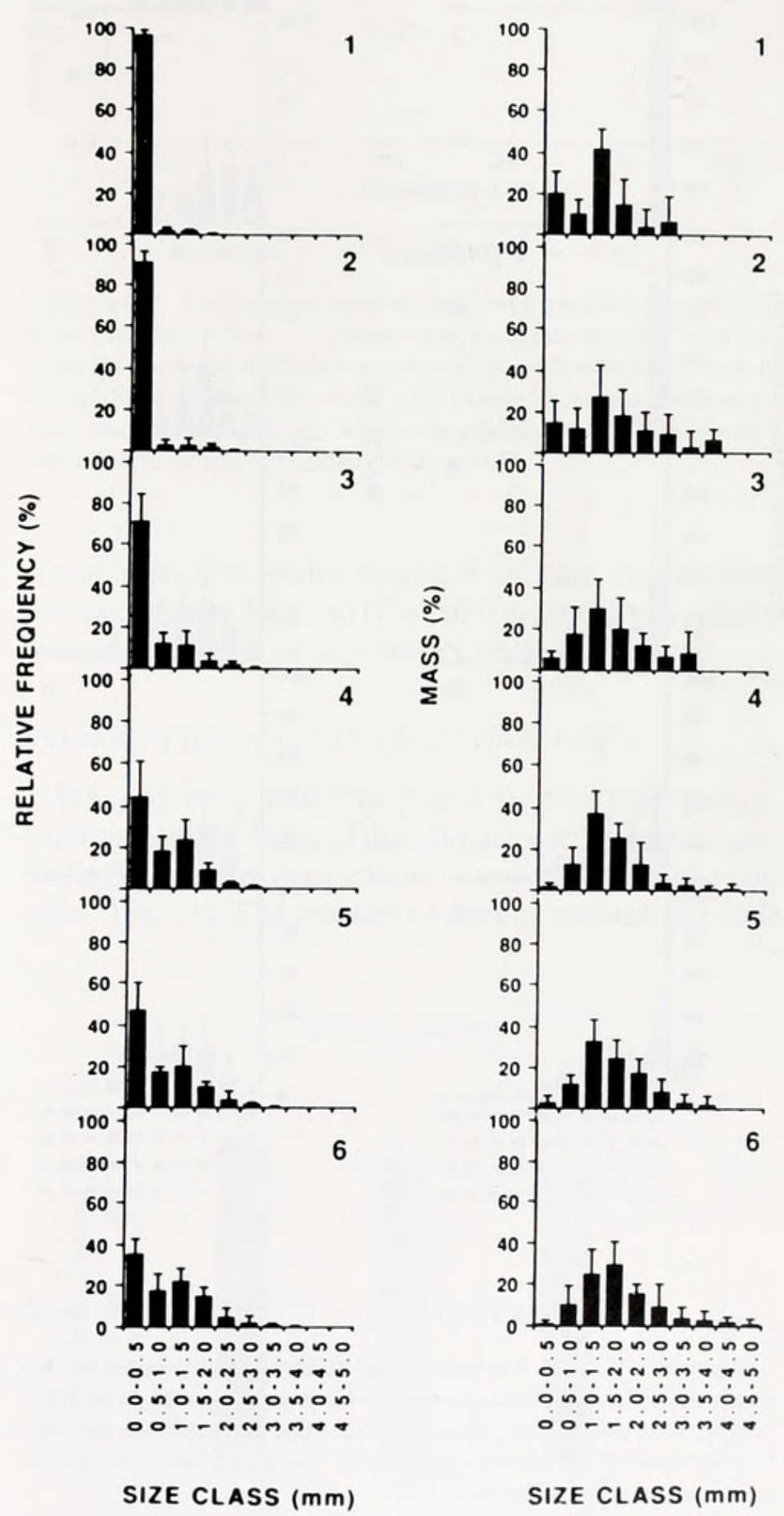

Figure 5. Relative frequencies and masses of sclerites within ten length classes from six locations within colonies of Sinularia sp. Samples were taken along transects from the tips of the colonies (location 1) to the bases of the colonies (location 6). The values for each size class are means from five colonies $\pm 1 \mathrm{SD}$ 
SINULARIA POLYDACTYLA

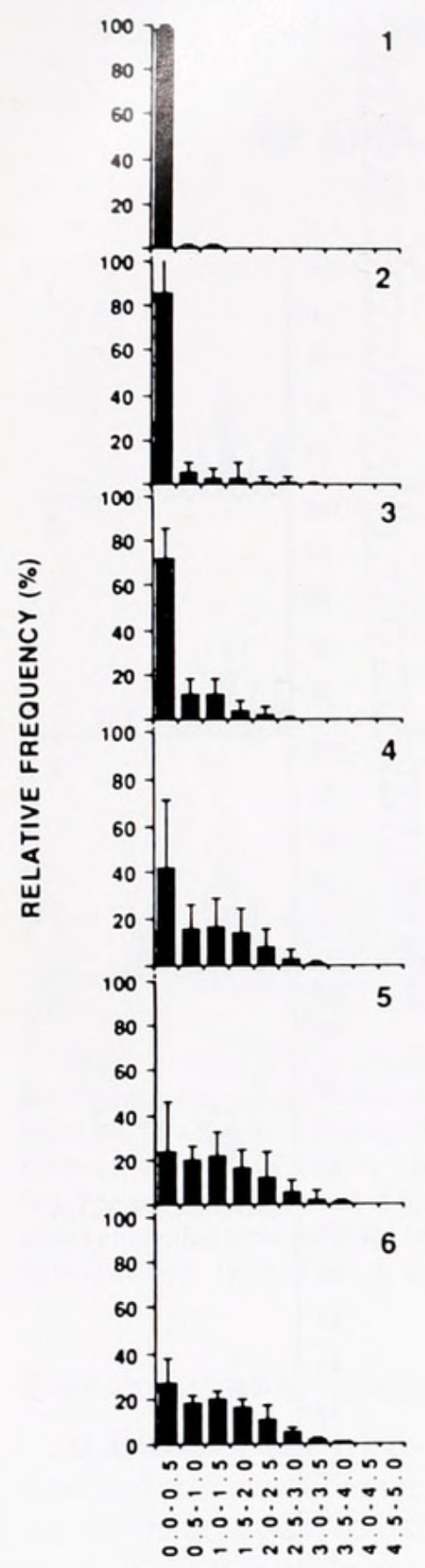

SIZE CLASS $(\mathrm{mm})$

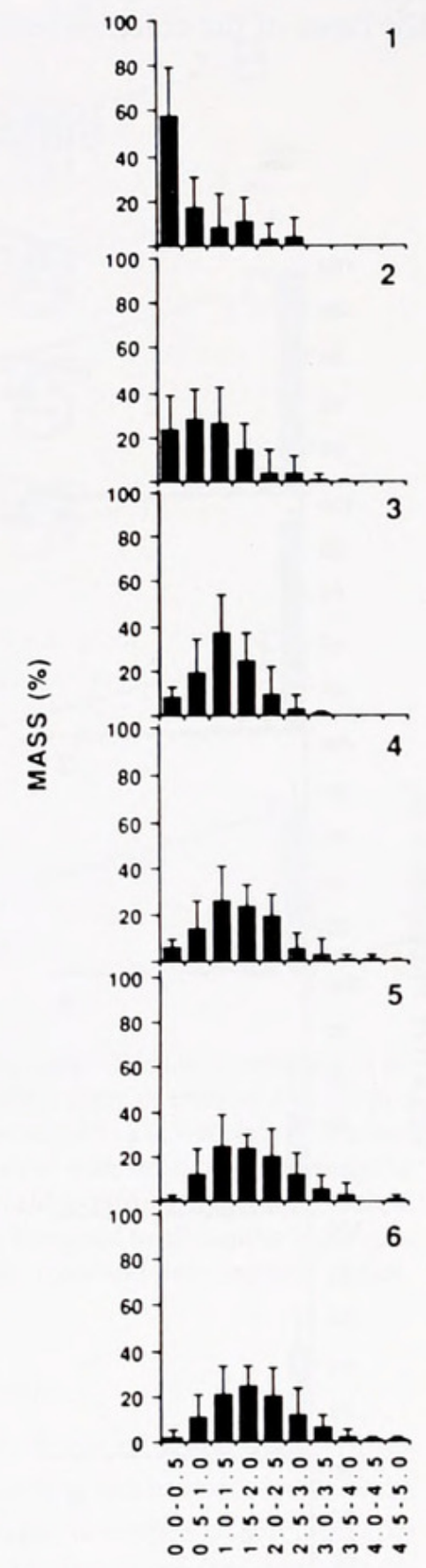

SIZE CLASS $(\mathrm{mm})$

Figure 6. Relative frequencies and masses of sclerites within ten length classes from six locations within colonies of Sinularia polydactyla. Samples were taken along transects from the tips of the colonies (location 1) to the bases of the colonies (location 6). The values for each size class are means from five colonies $\pm 1 \mathrm{SD}$.

The ability of Sinularia sclerites to deter feeding was dependent upon the concentration of sclerites added to the artificial diet. At the low concentrations of $10 \%$ by

dry weight, none of the sclerites from either bases or tips were significantly deterrent (Figs. 9, 10). Artificial diets containing sclerites from the bases of the colonies at $10 \%$ by dry weight were consumed at approximately equal rates

\section{SINULARIA MAXIMA}

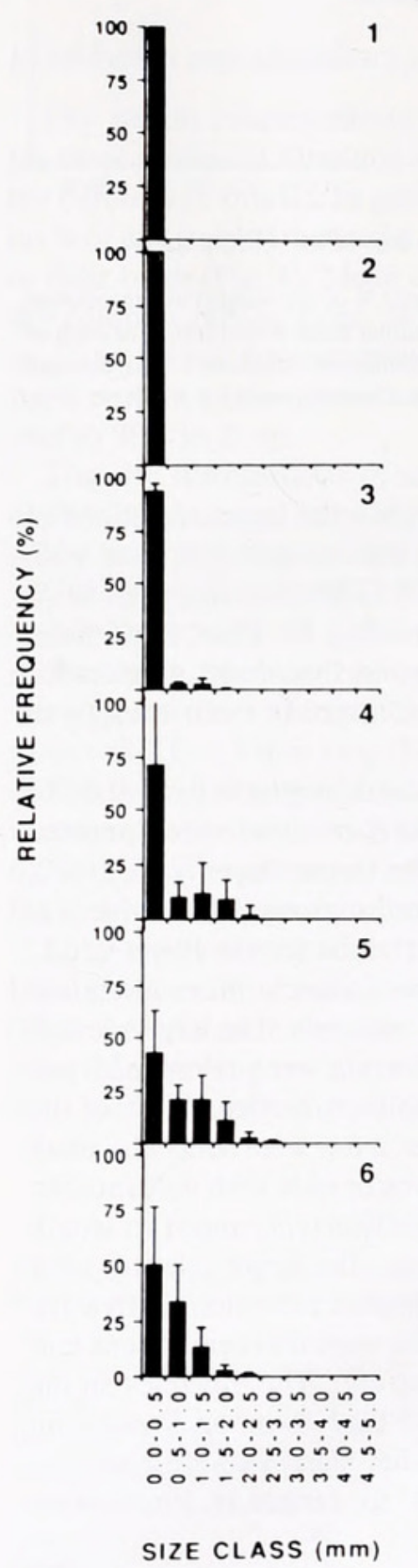

Figure 7. Relative frequencies and masses of sclerites within ten length classes from six locations within colonies of Sinularia maxima. Samples were taken along transects from the tips of the colonies (location 1) to the bases of the colonies (location 6). The values for each size class are means from five colonies $\pm 1 \mathrm{SD}$. 


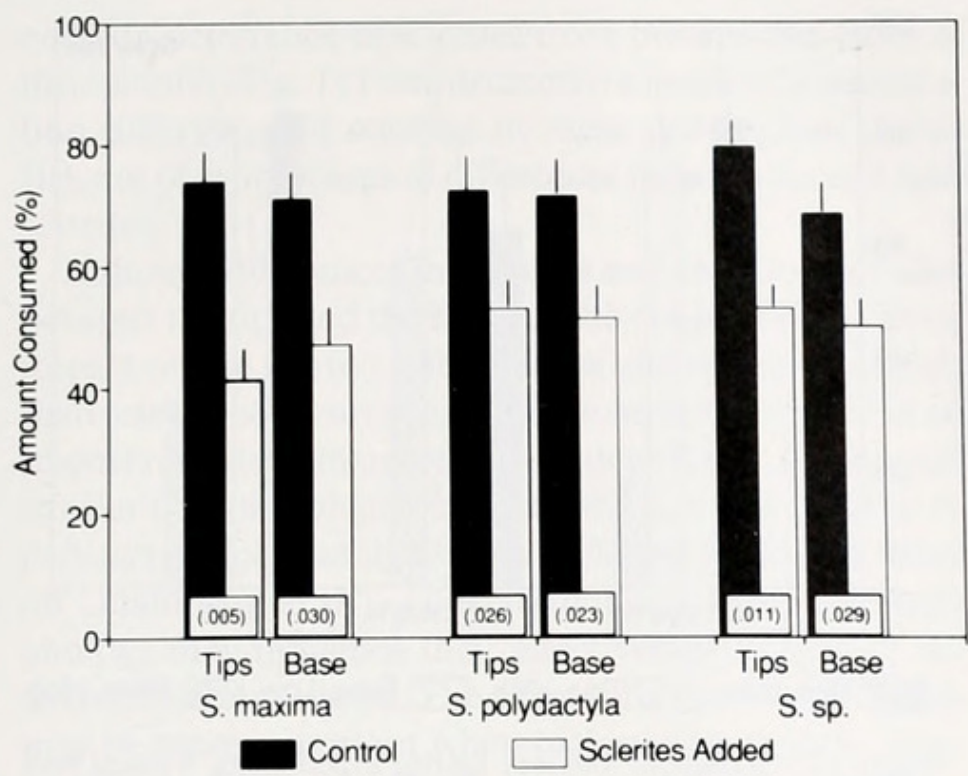

Figure 8. Mean amount consumed by generalist fishes at Fingers Reef of artificial diet with sclerites from Sinularia spp. (white bars) and without sclerites (dark bars). Numbers in parentheses at the bases of the bars are $P$ values from Wilcoxon Signed Ranks tests for paired comparisons.

to artificial diet lacking sclerites (Fig. 9); artificial diets containing tip sclerites from S. maxima and S. sp. at $10 \%$ by dry weight were consumed at a greater rate than the control diets (Fig. 10). The relative consumption rate of artificial diets with sclerites relative to control diets lacking sclerites decreased with increasing sclerite concentration. All of the sclerites except those from the bases of $S$. sp. were significantly deterrent $(P<0.05)$ at concentrations

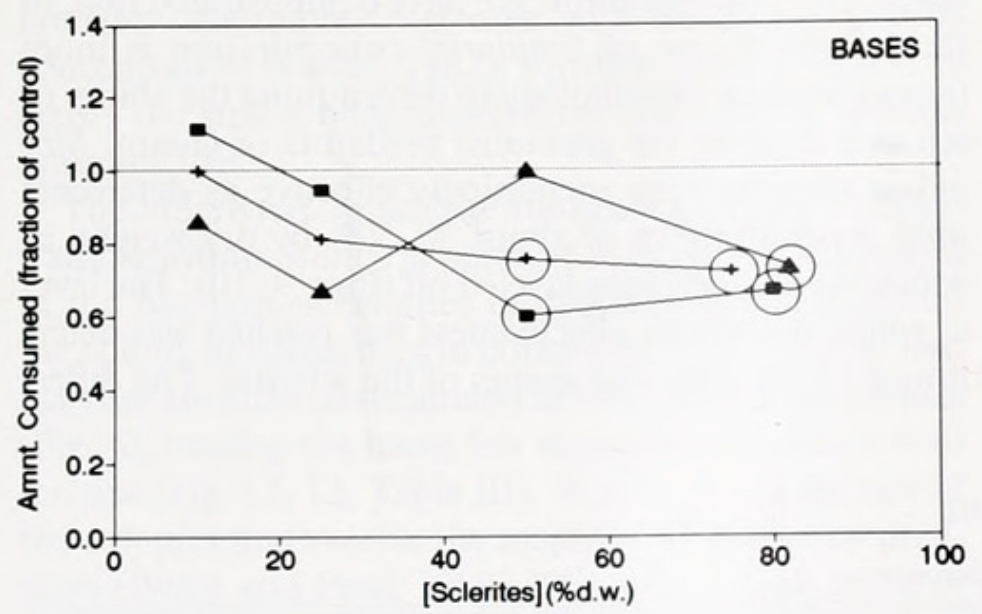

- S. maxima + S. polydactyla A S. sp.

Figure 9. Feeding deterrence of Sinularia base sclerites towards generalist carnivorous fishes at different sclerite concentrations. Points represent the mean feeding rate on artificial diet with sclerites relative to control diet lacking sclerites. Each value represents the results of a single two-way choice experiment. Circled points denote experiments in which sclerites were significantly deterrent $(P<0.05)$.

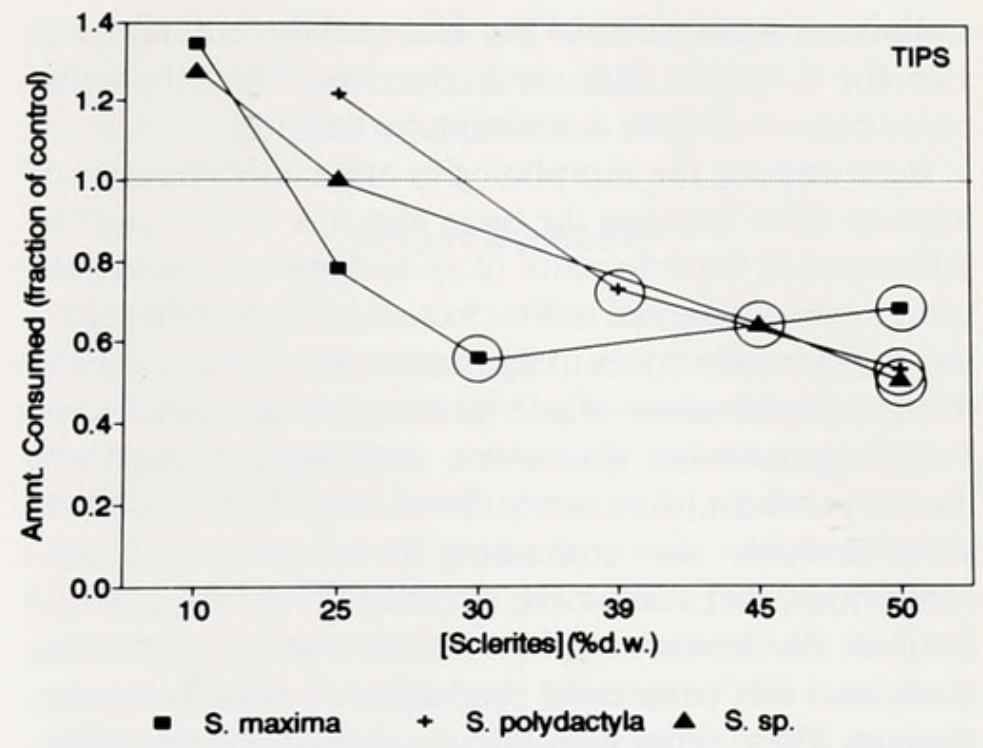

Figure 10. Feeding deterrence of Sinularia tip sclerites towards generalist carnivorous fishes at different sclerite concentrations. Points represent the mean feeding rate on artificial diet with sclerites relative to control diet lacking sclerites. Each value represents the results of a single two-way choice experiment. Circled points denote experiments in which sclerites were significantly deterrent $(P<0.05)$.

greater than $25 \%$ by dry weight; $S$. sp. base sclerites were not significantly deterrent $(P>0.05)$ at $50 \%$ by dry weight, but were deterrent at $82 \%$ by dry weight.

\section{Intracolony differences in sclerite effectiveness}

When directly tested in paired feeding experiments, sclerites from the bases of the colonies were more effective feeding deterrents than sclerites from the tips of the colonies (Fig. 11). The amount of feeding on artificial diets

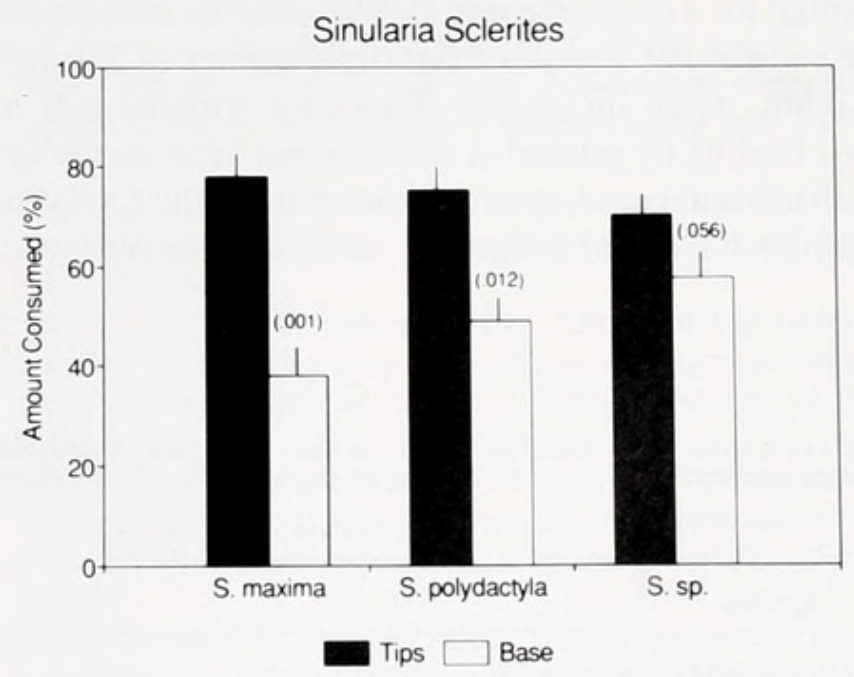

Figure 11. Mean amount consumed by generalist carnivorous fishes of artificial diet containing tip (dark bars) and base (white bars) sclerites in paired feeding experiments ( $\mathrm{n}=19$ to 20 ). Numbers in parentheses are $P$ values from Wilcoxon Signed Ranks tests for paired comparisons. 
containing sclerites from the bases of the colonies was $18 \%$ (in $S . \mathrm{sp}$.) to $51 \%$ (in S. maxima) lower than the consumption of diets containing tip sclerites.

Because both the morphologies and concentrations of sclerites differ between the bases and tips of the colonies, differences in the deterrence of tip and base sclerites could result from differences in the sizes and shapes of the sclerites or from differences in their amounts. To sort out the relative contributions of sclerite morphology and concentration to predator deterrence, experiments were conducted in which fishes were offered four choices of foods simultaneously: diet containing tip sclerites at tip concentrations, diet containing tip sclerites at base concentrations, diet containing base sclerites at tip concentrations, and diet containing base sclerites at base concentrations. These experiments demonstrated that the ability of sclerites to deter feeding was dependent upon both the morphology of the sclerites and their concentrations; however, concentration is a more important factor than morphology in Sinularia spp. (Table III). Feeding rates were higher on artificial diets containing sclerites at the lower tip concentrations than the higher base concentrations, regardless of sclerite type (Fig. 12). In S. maxima, the smaller tip sclerites were less effective deterrents than the larger base sclerites at high concentrations, but were only slightly less effective at low concentrations. In $S$. polydactyla, tip sclerites were more effective deterrents than base sclerites at both high and low concentrations. In $S$. sp., tip and base sclerites were equally effective at low concentrations; however, at high concentrations, tip sclerites were less effective deterrents.

\section{Discussion}

This and other studies have clearly demonstrated the potential for a defensive role for alcyonarian sclerites. We have shown that sclerites from three species of Sinularia in Guam, when incorporated into an artificial diet, reduced feeding by generalist carnivorous fishes in the field (Fig. 4). Similar studies with sclerites from the Caribbean gorgonians Pseudopterogorgia acerosa (Harvell et al.,

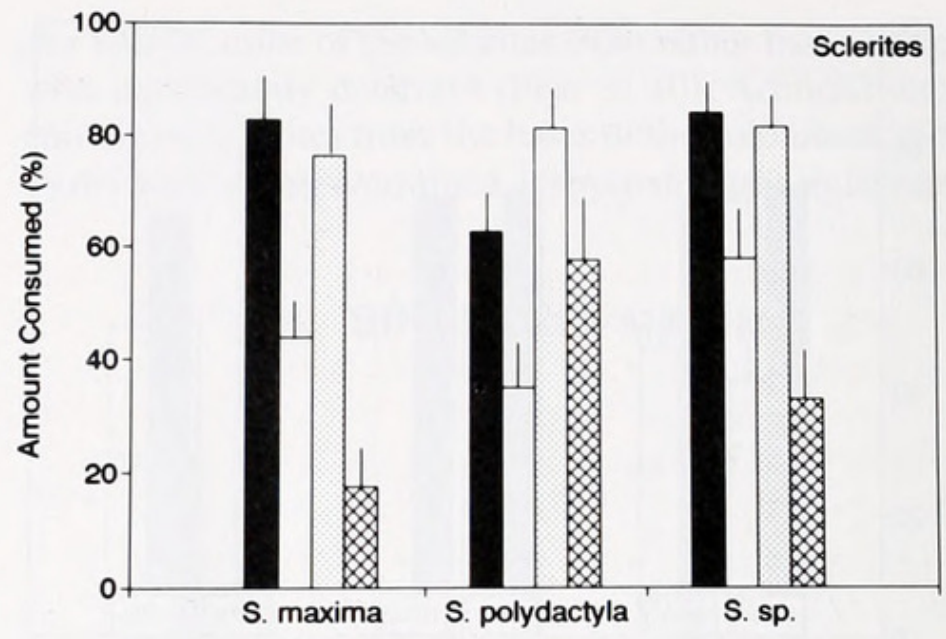

Tips, Low $\square$ Tips, High $\square$ Base, Low High

Figure 12. Results of four-way feeding experiments. Vertical bars represent mean feeding rates on tip or base sclerites at natural tip (low) or natural base (high) concentrations. Vertical lines represent $\pm 1 \mathrm{SE}$. Statistical analyses are presented in Table III.

1988) and Gorgonia ventalina (Van Alstyne and Paul, in press) have also demonstrated that sclerites can deter feeding in the field. However, not all alcyonarian sclerites are deterrent at natural concentrations. For example, sclerites from the white whip, Junceela sp., naturally occur at concentrations of $\sim 45 \%$ by dry weight, a similar concentration to those found in Sinularia; but, Junceela sclerites are not deterrent towards carnivorous fishes at natural dry weight concentrations (Paul and Van Alstyne, in prep.).

Invertebrate spicules and sclerites vary widely in size, shape, and concentration. We have demonstrated that, in these three species of Sinularia, concentration is more important than morphology in determining the ability of sclerites to deter the generalist predators of Guam. Sinularia sclerites were increasingly effective as deterrents until concentrations of about $30-50 \%$ by dry weight, at which point deterrence leveled off (Figs. 9, 10). The level at which maximum effectiveness was reached was determined by the sizes and shapes of the sclerites. The differ-

Table III

Results of two-way Kruskal-Wallis tests on data from four choice feeding experiments

\begin{tabular}{|c|c|c|c|c|c|c|}
\hline \multirow[b]{2}{*}{ Species } & \multicolumn{2}{|c|}{ Location of sclerites } & \multicolumn{2}{|c|}{ Concentration of sclerites } & \multicolumn{2}{|c|}{ Location* ${ }^{*}$ concentration } \\
\hline & $\mathrm{H}$ & $P$ & $\mathrm{H}$ & $P$ & $\mathrm{H}$ & $P$ \\
\hline Sinularia maxima & 2.696 & 0.096 & 29.13 & 0.000 & 1.265 & 0.260 \\
\hline Sinularia polydactyla & 7.057 & 0.008 & 9.136 & 0.003 & 0.071 & 0.786 \\
\hline Sinularia sp. & 1.972 & 0.156 & 17.39 & 0.000 & 1.238 & 0.265 \\
\hline
\end{tabular}

Data are presented in Figure 12. 
ences in deterrence of sclerites from the tips and bases of the colonies (Fig. 11) was primarily a result of concentration differences of sclerites in these two regions (Table III), not of morphological differences between tip and base sclerites.

Although differences in the sizes and shapes of sclerites between the tips and the bases of the colonies had a lesser impact on the relative effectiveness of structural defenses than sclerite concentration, sclerite morphology is still an important determinant of feeding deterrence. Differences in sclerite morphologies between the tips and bases of $S$. polydactyla colonies significantly affected feeding by fishes off Guam (Table III). Two components of sclerite morphology may influence their effectiveness as feeding deterrents: size and shape. The effects of sclerite morphology may be more important when making interspecific comparisons of deterrence. For example, sclerites from Junceela sp. do not deter feeding by fishes at Fingers Reef (Paul and Van Alstyne, in prep.). These Junceela sclerites are similar in size and concentration to many of the smaller Sinularia sclerites, but, they differ in shape (Paul and Van Alstyne, in prep.). Sclerite shape probably has a significant effect on function, particularly in determining the ability of the sclerite to deter potential predators.

Although our experiments have demonstrated that Sinularia sclerites can deter feeding by fishes, predator deterrence may not be the primary function of these structures. Spicules from marine invertebrates also play a role in structural support for colonies, increasing the stiffness of connective tissues by acting like reinforcing fibers (Koehl, 1982). Small sclerites tend to increase colony stiffness more than large sclerites; however, stiffness, like predator deterrence, increases with increasing sclerite concentration (Koehl, 1982). Further work is needed to clarify the structural and defensive functions of invertebrate spicules.

The differences in sclerite morphologies and concentrations within Sinularia colonies may reflect differences in the function of sclerites in different locations within the colony or differences in constraints upon sclerite use. Sclerites are most concentrated in the bases of the colonies (Fig. 4), making the bases less susceptible to attack than the tips (Fig. 12, 13, Table III). However, it is the tips of the colonies that receive the majority of attacks by predators (Wylie and Paul, 1989). The lack of high levels of sclerites in the colony tips may reflect constraints on sclerite use. The presence of large quantities of sclerites may interfere with the functioning of the soft coral polyps, which are found only in the tips of the colonies. Alternatively, sclerites in the bases of the colonies may serve primarily as structural support rather than predator deterrents. The presence of high concentrations of predatordeterrent extracts in the tips of the colonies (Wylie and
Paul, 1989; Van Alstyne et al., in prep.) supports the hypothesis that sclerite concentrations in the tips of colonies are under functional constraints.

\section{Acknowledgments}

The authors are grateful to D. Carandang-Liberty, K. Foster, K. Kuetzing, H. Sanger, and K. Sonada for the many hours spent attaching o-rings onto safety pins. We are also grateful to these individuals and the attendees of the UOG POETS club for spending many more hours taking the o-rings off safety pins. We are indebted to D. Carandang-Liberty, K. Foster, B. Irish, L. Meyer, H. Sanger, and K. Sonada for their assistance with the field experiments. We also thank S. Murray of the California State University at Fullerton for use of his image analysis system, J. Smith of CSUF for advice on statistical analyses, and A.O.D. Willows and the staff of the Friday Harbor Laboratories for the use of the scanning electron microscopy facilities. This manuscript greatly benefitted from the comments of two anonymous reviewers. This research was funded by NIH grant GM 38624 to VJP and a Guyer postdoctoral fellowship from the University of Wisconsin to KLV. This is contribution number 311 of the University of Guam Marine Laboratory.

\section{Literature Cited}

Bayer, F. M. 1956. Octocorallia. Pp. F166-F231 in Treatise on Invertebrate Paleontology, Part F, Coelenterata, R. C. Moore, ed. University of Kansas Press, Lawrence, KS.

Bayer, F. M. 1961. The shallow water Octocorallia of the West Indian region. Studies on the Fauna of Curacao and Other Caribbean Islands 12: $1-373$.

Bayer, F. M., M. Grasshoff, and J. Verseveldt. 1983. Illustrated Trilingual Glossary of Morphological and Anatomical Terms Applied to Octocorallia. E. J. Brill, Leiden. 75 pp.

Coll, J. C., D. M. Tapiolas, B. F. Bowden, L. Webb, and H. Marsh. 1983. Transformation of soft coral (Coelenterata: Octocorallia) terpenes by Ovula ovum (Mollusca: Prosobranchia). Mar. Biol. 74: $35-40$.

Gawel, M. J. 1977. The common shallow-water soft corals (Alcyonacea) of Guam. M.Sc. Thesis, University of Guam, Agana, Guam. 201 pp.

Harvell, C. D., and W. Fenical. 1989. Chemical and structural defenses of Caribbean gorgonians (Pseudopterogorgia spp.): intracolony localization of defense. Limnol. Oceanogr. 34: 380387.

Harvell, C. D., W. Fenical, and C. H. Greene. 1988. Chemical and structural defenses of Caribbean gorgonians (Pseudopterogorgia spp.) I: Development of an in situ feeding assay. Mar. Ecol. Prog. Ser. 49: 287-294.

Harvell, C. D., and T. H. Suchanek. 1987. Partial predation on tropical gorgonians by Cyphoma gibbosum (Gastropoda). Mar. Ecol. Prog. Ser. 38: 37-44.

Kingsley, R. J. 1984. Spicule formation in the invertebrates with special reference to the gorgonian Leptogorgia virgulata. Am. Zool. 24: 883891. 
Kingsley, R. J., M. Tsuzaki, N. Watabe, and G. L. Mechanic. 1990. Collagen in the spicule organic matrix of the gorgonian Leptogorgia virgulata. Biol. Bull. 179: 207-213.

Koehl, M. A. R. 1982. Mechanical design of spicule-reinforced connective tissue. J. Exp. Biol. 98: 239-268.

LaBarre, S., J. C. Coll, and P. W. Sammarco. 1986. Defensive strategies of soft corals (Coelenterata: Octocorallia) of the Great Barrier Reef. II: The relationship between toxicity and feeding deterrence. Biol. Bull. 171: 625-636.

Paul, V. J., and K. L. Van Alstyne. 1987. Chemical defense and chemical variation in some tropical Pacific species of Halimeda (Halimedaceae; Chlorophyta). Coral Reefs 6: 263-269.

Pawlik, J. R., M. T. Burch, and W. Fenical. 1987. Patterns of chemical defense among Caribbean gorgonian corals: a preliminary survey. $J$. Exp. Mar. Biol. Ecol. 108: 55-66.

Sammarco, P. W., S. LaBarre, and J. C. Coll. 1987. Defensive strategies of soft corals (Coelenterata: Octocorallia) of the Great Barrier Reef: III. The relationship between icthyotoxicity and morphology. Oecologia 74: 93-101.
Tursch, B., and A. Tursch. 1982. The soft coral community on a sheltered reef quadrat at Laing Island (Papua New Guinea). Mar. Biol. 68: $321-332$.

Van Alstyne, K. L., and V. J. Paul. 1992. Chemical and structural antipredator deterrents in the sea fan Gorgonia ventalina: effects against generalist and specialist predators. Coral Reefs In press.

Verseveldt, J. 1977. Octocorallia from various localities in the Pacific Ocean. Zool. Verhand. Leiden 150: 1-52.

Verseveldt, J. 1980. A revision of the genus Sinularia May (Octocorallia, Alcyonacea). Zool. Verh. Leiden 178: 1-165.

Wylie, C. R. 1988. Chemical defenses in three species of Sinularia (Coelenterata, Alcyonacea): effects against the predator Cheatodon unimaculatus (Perciformes). M.Sc. Thesis, University of Guam, Mangilao, Guam. 38 pp.

Wylie, C. R., and V. J. Paul. 1989. Chemical defenses in three species of Sinularia (Coelenterata, Alcyonacea): effects against generalist predators and the butterflyfish Chaetodon unimaculatus Bloch. $J$. Exp. Mar. Biol. Ecol. 129: 141-160. 


\section{$2 \mathrm{BHL}$ Biodiversity Heritage Library}

Van Alstyne, Kathryn Lyn et al. 1992. "Antipredator Defenses in Tropical Pacific Soft Corals (Coelenterata: Alcyonacea). I. Sclerites as Defenses Against Generalist Carnivorous Fishes." The Biological bulletin 182, 231-240. https://doi.org/10.2307/1542116.

View This Item Online: https://www.biodiversitylibrary.org/item/17417

DOI: https://doi.org/10.2307/1542116

Permalink: https://www.biodiversitylibrary.org/partpdf/8131

\section{Holding Institution}

MBLWHOI Library

\section{Sponsored by}

MBLWHOI Library

\section{Copyright \& Reuse}

Copyright Status: In copyright. Digitized with the permission of the rights holder.

License: http://creativecommons.org/licenses/by-nc-sa/3.0/

Rights: https://biodiversitylibrary.org/permissions

This document was created from content at the Biodiversity Heritage Library, the world's largest open access digital library for biodiversity literature and archives. Visit BHL at https://www.biodiversitylibrary.org. 